\title{
Fundamental Issues in Implementing an Ambulatory Care Electronic Health Record
}

\author{
Ann Scheck McAlearney, ScD, MS, Jennifer L. Hefner, PhD, Cynthia Sieck, PhD, \\ Milisa Rizer, MD, and Timothy R. Huerta, PhD
}

Background: The use of a fully functional electronic health record (EHR) system is linked to improved quality measures. However, almost half of ambulatory providers with an EHR do not use the full functionality. Attempts to encourage optimal use of EHRs must address barriers associated with the need to change medical practice.

Methods: Our primary research question was, what are the fundamental issues associated with the need to change medical practice that created barriers to electronic health record (EHR) implementation and use? In this qualitative study we analyzed the data from 47 interviews with administrative and physician informants and 6 focus groups including 35 practicing physicians across 6 health care organizations that were deemed to be successful with ambulatory EHR implementation.

Results: Comments from informants revealed 6 fundamental issues: (1) need to change practice style; (2) threat to professionalism; (3) shift of expertise; (4) required changes to interactions with patients; (5) concern about the impact on medical education and training; and (6) concern about effects on clinical care.

Conclusion: The physician experience must be at the forefront of efforts to increase the rate of ambulatory physician use of the full functionalities of an EHR. The issues highlighted here illuminate potential points of intervention when engaging physicians to ensure optimal use of EHRs. ( $\mathrm{J}$ Am Board Fam Med 2015;28:55-64.)

Keywords: Electronic Medical Records, Practice Management, Qualitative Research

In 2012, $72 \%$ of ambulatory physician offices in the United States reported full or partial electronic health record (EHR) use. ${ }^{1,2}$ However, only $27 \%$ of physicians planning to apply for meaningful use

This article was externally peer reviewed.

Submitted 4 March 2014; revised 12 August 2014; accepted 15 August 2014.

From the Departments of Family Medicine (ASM, JLH, $\mathrm{CS}, \mathrm{MR}, \mathrm{TRH})$ and Biomedical Informatics (MR, TRH), The Ohio State University College of Medicine, Columbus; the Division of Health Services Management and Policy, The Ohio State University College of Public Health, Columbus (ASM); and the Department of Corporate Strategy and Innovation, École Polytechnique Fédérale de Lausanne, Lausanne, Switzerland (ASM).

Funding: This research was funded by the Center for Health Management Research. The study sponsors had no involvement in the study design; in the collection, analysis, and interpretation of data; in writing the manuscript; or in the decision to submit the manuscript for publication.

Conflict of interest: none declared.

Corresponding author: Ann Scheck McAlearney, ScD, MS, Department of Family Medicine, Ohio State University College of Medicine, 273 Northwood and High Building, 2231 North High St, Columbus, OH 43201 (E-mail: Ann.McAlearney@osumc.edu).
(MU) incentives had EHRs capable of meeting stage 1 core MU objectives. ${ }^{1,2}$ Functionalities of EHR systems vary, ${ }^{3}$ as does the use of EHR functionalities by individual physicians within a single practice. $^{4}$ In 2012 only $40 \%$ of US ambulatory care providers used a fully functional system including patient history and demographics, problem lists, physician clinical notes, comprehensive medications and allergies lists, computerized prescription orders, and laboratory and imaging results viewed electronically, ${ }^{1,5}$ suggesting that reported use of an EHR in an ambulatory setting cannot be equated with meaningful integration of an EHR into practice. EHR implementation studies must consider how changes in practice patterns and professional concerns could hinder full implementation and integration.

Previous research describes individual and organizational barriers to EHR use. ${ }^{2,6-9}$ Organizational barriers include financial costs, potential loss of productivity and therefore income, and lack of 
standardization across environments. ${ }^{8,10,11}$ Frequently cited individual barriers focus on financial, technical, time, psychological, social, legal, and organizational concerns. ${ }^{12,13}$ Barriers specific to physicians include participation in EHR selection and planning; physician compensation, that is, effects of EHR use on fee-for-service reimbursement rates ${ }^{13}$; and training time, which may decrease productivity. ${ }^{14,15}$ Designing interventions to ameliorate these barriers requires an in-depth understanding of the physician experience. Our study focuses on how the professional life of physicians changes with EHR implementation and how their clinical practice is affected.

Understanding physicians' and administrators' perceptions about the physician experience of EHR implementation is important because of the potential for fully functional EHR systems to reduce costs and improve quality. ${ }^{2,16}$ Cost-benefit analyses have documented long-term savings and a slowing of ambulatory care cost growth. ${ }^{17-19}$ Providers perceive efficiency and quality of care improvements from electronic patient information exchange that is a component of EHRs. ${ }^{20}$ Moreover, quantitative, fully functional EHRs in ambulatory care are associated with significant improvement in provider performance ${ }^{18,21}$ and with improved Healthcare Effectiveness Data and Information Set quality measures. $^{22}$

This article describes physician and administrative perspectives about how adoption and implementation of an EHR system affects physicians' clinical practice. The overall goal of this large research study was to improve the understanding of the facilitators of ambulatory EHR system implementation. This article focuses on the barriers physicians face on both a personal and practice level during the adoption and use of such systems. Our primary research question was, What are the fundamental issues associated with the need to change medical practices and physicians' behaviors that create barriers to EHR implementation and use?

\section{Methods}

\section{Research Design}

This was a qualitative study that analyzed data from key informant interviews and focus groups. This study protocol was approved by The Ohio State University Behavioral and Social Sciences Institutional Review Board.

\section{Identification of Best Practice Sites}

Six sites were selected for study based on successful implementation of EHR systems in ambulatory care. The criteria used to define success included receipt of the Health care Information Management Systems Society annual Davies Award for ambulatory EHRs within the past 5 years combined with recognition as a "most wired" hospital by the Hospital and Health Network's annual benchmark survey. Input from a project advisory committee comprising representatives from industry and academia with expertise in health information technology implementation allowed the research team to finalize a list of 10 potential study sites. From this list, 6 health systems across the United States were identified to provide sufficient geographic and organizational variability; all target study sites agreed to participate.

\section{Study Participants}

The 6 study sites were large health systems from the eastern, northern, and central regions of the United States, including 3 large metropolitan areas, a suburb of a large metropolitan area, a midsized city of about 100,000 people, and a town of about 30,000. All sites had implemented EHR systems between 1 and 5 years before data collection in 2008. A total of 47 physician and 35 administrative informants participated across the study sites (Table 1). Administrative key informants included organizational leaders and managers, information systems leaders and professionals, and staff members. Physician interviewees and focus group participants included physicians in practice, physicians

\section{Table 1. Participants in Interviews and Focus Groups} across the 6 Study Sites

Participants (n)

$\begin{array}{lr}\text { Administrators } & \\ \text { Leaders/managers } & 18 \\ \text { Information technology professionals and } & 13 \\ \text { leaders } & \\ \text { Staff } & 4 \\ \text { Total } & 35 \\ \text { Physicians } & \\ \text { Physicians in practice (attendings, private } & 26 \\ \text { practice physicians) } & \\ \text { Physicians in training (interns, residents) } & 17 \\ \text { Physician leaders } & 4 \\ \text { Total } & 47\end{array}$


in training, and physician leaders in the health care organizations we studied.

\section{Focus Groups and Key Informant Interviews}

Interviews with key informants lasted 30 to 60 minutes and consisted of a series of open-ended questions with follow-up question probes. All interviews were audio-recorded and transcribed for later analysis following rigorous standards for qualitative research. ${ }^{23,24}$ The research team also conducted 6 physician focus groups guided by an indepth interview guide containing open-ended questions. A trained facilitator who was assisted by a co-moderator led each group. Sessions lasted 60 to 90 minutes and were audio-recorded and transcribed before analysis.

The interview guide was similar for both administrators and physicians and was used for both inperson and telephonic interviews. In the interview guide, the "Implementation: Barriers/Challenges and Facilitators" section included specific questions: "What have been the biggest facilitators and barriers to physicians' adoption of EHR among your physicians?" and "Please briefly describe your process for implementing your ambulatory EHR. What worked well? What did not? What has changed over time?" Additional questions included queries about physician readiness to change assessments, financial incentives for physicians, and physician champions within the organization. A separate guide that included similar questions was used for focus group sessions. A coding dictionary was developed (described in the next section) to organize data from responses to interview and focus group questions into themes that address the research question.

\section{Analysis}

Throughout the data collection process, we reviewed interview and focus group transcripts and discussed preliminary findings. In the analysis phase we used a constant comparative analytic approach including both inductive and deductive methods to analyze the transcripts from both the key informant interviews and the focus groups. ${ }^{25}$ First, a coding team led by the lead investigator (ASM) identified broad themes and developed a preliminary coding dictionary. This dictionary included a list of code lists and a coding frame that was applied across the interview and focus group data. The broad code "physician perspective" was defined as physicians' views about how implementing an EHR changes their work and/or relationship to patients from either the physician or administrator perspective. This code was applied across comments in the transcript any time this topic was mentioned. All members of the coding team first coded 3 transcripts and compared their results, clarifying any differences that arose. This step was included to ensure consistency among coders. After coding, the data were classified into categories of findings following the methods described by Constas. ${ }^{26}$ During the coding and classification process the team met on a regular basis to discuss the process and reach consensus on emerging themes. The analysis was conducted using Atlas.ti qualitative data analysis software (version 6.0; http://atlasti.com/) that allowed detailed coding and formal exploration of patterns and themes within the data. ${ }^{27}$

\section{Results}

Comments from both physician and administrative informants enabled us to characterize 6 fundamental issues that emerged as perceived barriers to physicians' adoption and use of EHR systems: (1) need to change practice style; (2) threat to professionalism; (3) shift of expertise; (4) required changes to interactions with patients; (5) concern about the impact on medical education and training; and (6) concern about the potential impact on clinical practice itself. Statements from both interviewees and focus group participants illustrated that these barriers were commonly recognized by study participants. Below we describe each of these issues in greater detail; illustrative comments provided in Table 2 present evidence that these issues were mentioned by both physician and administrative informants.

\section{Need to Change Practice Style}

The first issue that clearly emerged was the need for physicians to explicitly change their behaviors and activities to use an EHR. Even though the need for this change was straightforward, it was not always appreciated. As one administrator summarized, "the sentiment I hear a lot of times from doctors is 'I did not go to medical school to be a secretary." One physician noted, "we have a great deal of difficulty fitting the [EHR] system into the way we have to do business." An administrator 
Table 2. Physician and Administrator Comments from Interviews and Focus Groups Regarding the Need to Change Medical Practice to Accommodate Electronic Health Record Implementation

Representative Physician Comments Representative Administrator Comments

\begin{tabular}{c} 
Representative Physician Comments \\
\hline $\begin{array}{c}\text { Need to change } \\
\text { practice style }\end{array}$ \\
- "I do almost all of my documentation and things \\
before or after I leave the patient's room." \\
"I would not document the majority of my \\
"til the end. Once patients are out by 5 or $5: 30$, \\
then I sit down and do all my paperwork. And I \\
get home by $7: 30$. I'm dead and hungry and \\
cranky." \\
"It's far faster to dictate than it is to type."
\end{tabular}

Threat to professionalism

Shift of expertise

Changed interactions with patients
- "I've really gotten to the point that I don't do much in the patient room because what you find, you're sitting there struggling to write a prescription and the patient's looking at you like, 'What's wrong with you?' You know, I mean, you really, I think, lose a lot of credibility when you're struggling or getting an order written and most people are pretty understanding yet. At the same time you feel like you're not competent."

- "You become a data entry person. And I think we haven't come to terms with the fact that we have to insulate that thought process of the docs better than we are doing it."

- "Attendings have absolutely . . no idea what they're doing with [the EHR]."

- "Some of it's being accessible, some of it's being efficient with your time and not keeping your patients waiting, and you know the whole package is what medical care to me is and I think the EMR can flip it. It flips that relationship."

- "I think we have a unique perspective on [the EHR] as opposed to everyone else in the hospital . . . I feel that from an [EHR] knowledge standpoint, the interns are the ones in the hospital that are most knowledgeable."

- "I actually showed one of the attendings a shortcut that I, I said, 'You know, in our EMR stuff we can do this, this.' He said, 'Oh my gosh I've been using it for 4 years and I never knew that."”

- "Even if you can position it so you're sort of looking at the screen and the patient, I think there's always the feeling that the patient is going, 'Are they really thinking about what's on the computer or. ...' It's just a different relationship. And so I think that concerns almost every physician I've talked to."
- “...just the transition of going from a paper record to an electronic medical record-change. Some of our physicians, in that practice, some of them are a little bit older and you know it's not like they're 30 or 40 that had computers as part of their schooling and training."

- "And some people are better typists than othersthat comes into play."

- "They've done it for all these years, it works. They know, practices would know, "well if I put the chart on this side of the desk it means blah, and if these were this kind, I would put them over here, and these charts I put over here on the cart.' And over time the practice knew what all of that meant. Well if you're in electronic world, you don't have this side of the desk and the cart."

- "We're trying to standardize the way that they conduct their patient visit because they have to go through it screen by screen in the order that we offer them. That's not something physicians are used to."

- "They're a little embarrassed, quite frankly, by some of these documents that look like the computer examines the patient, this is the computer's opinion of what's there. Their medical judgment and you know, it's an ego thing. I mean we all have our style. We all like the way to do certain things. That gets lost in the shuffle."

- "It's very hard on the physicians, not only because we're now making them data entry people but the sequence of how they examine people, how they traditionally interviewed you and assessed you, could be disrupted because the EMR goes in one linear step. It's a linear thing."

- "And most of the docs, they coach each other. They're pretty good at it."

- "They sit there and say, 'Well how am I supposed to remember everything I'm going to do if I don't have something to write it on?' Well if you're really younger generation, you're used to working on the computer and you're used to doing that and then walk and talk to them and then ... 'oh ok,' and go back and you're not uncomfortable with that."

- "You usually have a doc with their face buried in the computer because they're dealing with this new thing that they're not used to and so the patient's like, 'Hey I'm over here' kind of thing." 


\begin{tabular}{|c|c|c|}
\hline & Representative Physician Comments & Representative Administrative Comments \\
\hline & $\begin{array}{l}\text { - "I think if you don't talk and you're just on } \\
\text { there and you're typing and you're looking in } \\
\text { data and you're sort of internally processing all } \\
\text { this stuff and the patients over here and they're } \\
\text { not just watching you do that, I think they feel } \\
\text { really alienated. Now, if you're on here and } \\
\text { you're saying, 'ok, well lets look at your old labs } \\
\text { here ... OK, I can see your cholesterol was . . } \\
\text { this . . . and oh I see we started you on this new } \\
\text { drug and . . . how've you been doing on that } \\
\text { drug?" }\end{array}$ & $\begin{array}{l}\text {-There are probably } 1 \text { or } 2 \text { having a really hard } \\
\text { time where they still can't find that groove, that } \\
\text { 'sweet spot' between interacting with the patient } \\
\text { and looking on the computer. And I think they } \\
\text { are at a disadvantage because having it right there } \\
\text { in the room and dynamically looking at it ... I } \\
\text { mean a lot of discussions that go on are "well, my } \\
\text { patient[s] feel alienated if I'm looking at my } \\
\text { computer screen."' }\end{array}$ \\
\hline $\begin{array}{l}\text { Impact on } \\
\text { medical } \\
\text { education }\end{array}$ & $\begin{array}{l}\text { - "We really effectively completely learned } 3 \\
\text { systems, outpatient, inpatient [EHR], and then } \\
\text { whatever the old one was called within those few } \\
\text { months. So in addition to being brand new } \\
\text { doctors, it's a lot." } \\
\text { - "Oh, nobody thinks anymore. Everybody stops } \\
\text { thinking, I mean, I think you just end up } \\
\text { becoming automated. You just sort of go, OK } \\
\text { did I go down my list? Did I fill all my little } \\
\text { criteria? OK, did I do this? And you're not } \\
\text { independently thinking anymore, you're sort of } \\
\text { just thinking toward the computer." }\end{array}$ & $\begin{array}{l}\text { - "When the student hasn't been brought up to } \\
\text { speed with [the EMR] or doesn't have a log on, } \\
\text { then the student's involvement is really } \\
\text { diminished in the clinic[,] also because they can't } \\
\text { really do their own notes or documentation and } \\
\text { we lose a teaching opportunity there as well." } \\
\text { - "Some of these young new nurses have never seen } \\
\text { a paper chart." }\end{array}$ \\
\hline $\begin{array}{l}\text { Impact on } \\
\text { clinical practice }\end{array}$ & $\begin{array}{l}\text { - "These aren't necessarily items that can be } \\
\text { created in smart phrases. You need to } \\
\text { understand who's making decisions . . . who's } \\
\text { able to make decisions for the patient, where is } \\
\text { his family, who can I contact, his other providers } \\
\text { who are providing psychiatric care. It's } \\
\text { extremely complicated." } \\
\text { "So there are some levels of detail with a family } \\
\text { history, with a medical history where maybe the } \\
\text { problems aren't in the available possibilities and } \\
\text { so it become[s] a question of you look } 3 \text { or } 4 \\
\text { times under different things and then you can't } \\
\text { find the phrase anywhere so do you type "other" } \\
\text { and then go and do free text over or do you just } \\
\text { not document that problem?" }\end{array}$ & $\begin{array}{l}\text { - "Even though physicians are very busy, they want } \\
\text { to give their patients time, they want to connect } \\
\text { with them and it's difficult to do that when you're } \\
\text { typing on a computer." } \\
\text { "They've got so many issues, and they're all very } \\
\text { complex. . . They didn't become a primary care } \\
\text { doctor and take this } 30 \text {-hour-a-week job, so that } \\
\text { they could work } 50 . \text {." }\end{array}$ \\
\hline
\end{tabular}

EHR, electronic health record; EMR, electronic medical record.

explained how the system required behavior changes: "Behaviors, yeah. I mean they were used to waiting until the nurse dropped all this stuff on the desk and then they went through it. They did not have to worry about the clinic when they were not sitting at the clinic location. Now they have to worry about clinic when they are sitting here in the office. Because we expect them to tend to it and it is a behavior change."

Informants often noted that this issue was experienced differently by physicians of different ages and types. With respect to age, one established physician summarized, "So, for us older guys, we're set in our ways, and we're really very efficient and productive in the old method. We do see down the road why it is going to be helpful. The younger guys pick it up as if it were nothing." Yet there was also reportedly more change required for certain types of physicians. As another physician explained, "the specialists in particular . . . they see very complex patients with very specific abnormalities or specific findings on tests and documenting all that is going to be difficult." This issue was also particularly apparent for physicians who rely heavily on dictation. One noted, "And now the hard part is ... documenting something more cognitive like, you know, your assessment and plan, that can take a lot of typing, whereas it is easier to dictate that."

\section{Threat to Professionalism}

The transition to electronic records was also considered a major threat to physicians' professionalism because of the corresponding requirement for practitioners to adhere to the requirements of the EHR, including electronic documentation and 
compliance with standard guidelines. As one physician lamented, "it forces you into [a] structured regimen, best practice, best flow, best whatever, but not individualized. What I've been doing for 20 years . . that goes out the window very quickly." While physicians and administrators noted that the concern was not that doctors had been doing the wrong things in the past, the new requirement to document, as well as the understanding that others could view what they had documented in the EHR, were acknowledged as potentially threatening to many physicians. One administrator described how this transition "was a little bit of difficulty having them change their mind-set that it is not just your clinic chart now, it is everyone's chart." Another administrative informant noted, "And guess what? Now we can check up on what you are documenting ... no one wants to be micromanaged, and that is what we're doing to these docs, basically." In addition, physicians were concerned about their inability to seem competent using computers and the EHR system. One established physician concerned about this transition complained that, "There is no way I am going to type in front of this patient." This reflection on the need to maintain integrity exemplified the loss of confidence and perceived competence many physicians expressed with the introduction of the EHR.

\section{Shift of Expertise}

A third barrier to changing medical practice was the notion that the transition to an EHR involved a shift in expertise and, correspondingly, a shift in the professional hierarchy. This reportedly occurred when junior physicians more comfortable with computers became EHR "experts" compared with their colleagues who had more clinical experience. One senior physician summarized this issue:

"[An] EMR is a funny thing. It can turn the whole relationship we have upside down. The old model was senior physicians have more knowledge, more wisdom, more experience and they taught the younger. ... And an EMR in my mind flips it on its head because it is no longer simply about experience, right? A lot of it is taking technology and bringing it to the point of care. So if you are somebody [who] can leverage more efficient order entry or more efficient prescription refills and you can leverage, you know, patient portal communication with your patient and you can leverage building evidence-based smart tools into your practice, you have all a sudden kind of flipped things around and said, "I can actually take a leap farther forward and I can do things that you who's been in practice for 20 years cannot."

Administrators shared this observation, noting how "Newer, younger physicians [who] have come out of training are really good at it."

\section{Changed Interactions With Patients}

The fourth practice change barrier that emerged involved how the introduction of an EHR caused physicians to change the way they interacted with their patients. As one physician explained, this change was profound: "I had to relearn how to look at a person, how to talk to them in the examination room, carrying a laptop, compared with what I used to do." Another physician considered the patient's view: "I've been polling my patients for a very long time. For 2 years, just randomly, 'How do you feel about having a computer in the room? How do you feel about me spending half the time looking at the computer screen?' And, I would say $\geq 95 \%$ have said 'I have no problem with it.' I think there are tricks to it." A physician leader explained how this balance could occur: "So the amount of time you spend eye-to-eye, face-to-face is much less, right, but you are engaging the patient and it reinforces their thought that you are working for me, you are looking at a computer screen, but wow, you really know that? Oh, you read that note that the doc ... oh you have that right there? Oh, you already got my mammogram report? I just had that done last night?' You know, that kind of dynamic." Yet many physician respondents were still concerned about this and perceived changed interactions as a barrier to EHR use. Further, the extent of this issue for physicians varied based on both patient needs and provider preferences. As a primary care physician commented, "the more complaints a patient has or the more items a patient needs to have addressed . . . the more challenging it is to document in real time and feel that you are providing compassionate care and listening to the patient."

\section{Impact on Medical Education}

The fifth barrier involved concerns the impact of the EHR on medical education. From a logistical 
perspective, administrative informants raised the issue that medical schools should be changing their approach so that new trainees would be more comfortable with electronic data. As one interviewee commented, "You need to be pulling all that stuff back into med school. Med school needs to be starting with it back here. It should not be introduced when you get into the department. They should be using this stuff way back here. So it is a whole mind-set change. They need to go back to med schools now and say, 'OK, and how do you get data on your medical records? Well you [learn this system]. You do not go to a piece of paper." A physician leader, who also was concerned about the changes inherent in EHR introductions, noted that another component of medical education could specifically include how to interact with the computer and patient at the same time. He noted, "One of the things we need to teach people over time is that new bedside manner. Because there is a new bedside manner. And some people had bad bedside before and they have bad bedside [now with an EHR]."

While much of the issue related to changes in medical education would likely resolve over time as newly trained physicians (and other clinicians) finish their education being trained entirely using EHRs, interviewees also expressed concern that the integration of EHRs and computer-based guidance into medicine might have a negative effect. One physician reflected that ". . . I kind of fear sometimes that the medical students and the younger people coming up will stop ... will lose their ability to think because the computer prompts you to do everything. You know, you go to put the medicine in, the allergies are here, benefits versus risk, it prompts you to do everything such that your brain quits working." This concern was echoed by physicians of different ages and experience levels, thus indicating the need to consider its impact as EHRs become more embedded in medical practice.

\section{Impact on Clinical Practice}

A sixth issue involved concern about the potential impact of an EHR system on clinical practice itself. One specific example mentioned by both physician and administrative informants involved how the changing requirements for documentation associated with the EHR could threaten the completeness of medical records. A physician noted how, with an EHR system, documentation had "become more generic and less specific in all aspects-and particularly the psychosocial aspects." Another reflected that "because it is long to type a lot of these things, I end up doing very abbreviated sentences and not, perhaps, including some of the details because it is too long." As an information technology professional commented, "Some things lend themselves to discrete elements, but there is also a story too, a story of what happened to the patient, etc. And a lot of the providers do not like to give that up because it tells more than just those numbers." The result, as one physician explained, was that "it becomes a disincentive to document well or you end up using your administrative academic time or nonwork time to catch up on abstractions." This comment was echoed by other physicians, noting that they might act differently based on their patients' complaints. One provider explained that "If I sense that the patient needs to have face-to-face time with me, then I actually will not document as much when I am in the room because I know they need that. Or if they are discussing a topic that is upsetting, or that they really need to feel like I am really listening to them."

\section{Discussion}

Frequently identified physician barriers to EHR implementation include a lack of participation in EHR selection and planning, a lack of consideration of the effect on physician compensation, a decrease in productivity during training time, the lack of a champion for the innovation, and the lack of supportive leadership., ${ }^{9-12-15}$ Another element critical to the success of health information technology implementations but not commonly considered in physician EHR barrier studies is consideration of the culture of the workplace. ${ }^{28,29}$ The findings of this study expand what is known about physician barriers to EHR implementation by highlighting the cultural shift required by physicians. We specifically highlight 6 elements of this cultural shift related to physicians' professional hierarchy, clinical workflow, and medical training. In Roger's ${ }^{30}$ Diffusion of Innovations Model, previously used to study ambulatory EHR implementation, the themes of compatibility (the degree to which an EHR fits users' values, needs, and past experiences) and reinvention (the extent to which an EHR can be tailored to fit within the context of current practice) have particular relevance to the 
cultural shift identified here. ${ }^{9}$ A "threat to professionalism" and "concern about the impact on medical education and training" fit within Roger's identified theme of compatibility, whereas "the need to change practice style," "required changes to interactions with patients," "a shift of expertise," and "concerns about impacts on clinical care" speak to Roger's conception of reinvention. Situating these elements within Roger's model gives our study theoretical support and also operationalizes the consideration of the cultural shift among physicians required during EHR implementation in ways outlined below.

The health information technology regional extension centers (HIT-RECs) funded by the Office of the National Coordinator for Health Information Technology aim to assist primary care providers with adoption and meaningful use of EHRs. ${ }^{31} \mathrm{~A}$ 2010 outline of the HIT-REC program discusses current implementation challenges and regional extension center solutions, which focus on assistance with technical, financial, reporting, and privacy and security concerns, ${ }^{31}$ specifically mentioning culture and workflow. The present study provides crucial information to assist HIT-REC trainers with operationalizing culture and workflow variables. The study findings also have important implications for EHR vendors. Many vendors have an education and implementation mission similar to that of HIT-RECs. In addition, vendors must take user feedback into account during system builds and redesigns. This study can inform future design modifications and vendor support activities.

The impact of EHR implementation on the process of medical education is a finding of particular interest. Administrators and physicians noted that not only do medical schools need to teach students to interact with an EHR, they also need to teach the integration of EHRs into the process of patient care. While the study of EHRs and medical education in its infancy, ${ }^{32,33}$ there is contention regarding whether EHRs help or hinder the educational process. ${ }^{34}$ Acknowledging the lack of a standardized process to incorporate EHRs into medical education curriculums, the reporter-interpretermanager-educator EMR scheme incorporates the use of EMRs into the context of the Accreditation Council for Graduate Medical Education core educational competencies. ${ }^{33}$ Further, recent research has noted opportunities to improve education around both data collection and retrieval of aggre- gate data that can allow physicians to learn from data trends. ${ }^{35}$ The findings of our study highlight the need for the proliferation of these types of training curricula.

Specific elements of the EHR that have been linked to increased patient quality may be the most difficult for individual physicians to implement, ${ }^{22}$ a potential explanation for the gap between EHR implementation and utilization of a fully functional system. ${ }^{1,3,4}$ Further exploration of the implementation process of specific EHR elements, as opposed to "EHR system implementation" as a single variable, could be conducted in a manner similar to the present study, with the inclusion of questions regarding specific EHR functionalities. Another area for future research is the potential link between individual elements of an EHR (and EHR systems) and the 6 issues identified here. If the goal is to increase the utilization of fully functional EHR systems, understanding how different types of EHR functionalities and systems impact the physician experience is critical.

\section{Limitations}

One limitation of this study is the small number of health systems that were contacted. The time and energy requirements associated with qualitative studies create significant barriers to larger-scale studies but allow in-depth investigation that is not possible on a larger scale. Further, this study's important preliminary findings can guide the development of future survey studies that can clarify themes among larger representative samples. In addition, the generalizability of our study may be limited by variation in the state of EHR development across sites and informants' familiarity with the EHR. However, recognizing that these variables differed by site and by EHR system, that the 6 main issues were consistently mentioned across informant types and sites gives strength to our claim that we have identified the most salient themes within this topic. An additional limitation is the inability of our study to link EHR implementation strategies to either clinical or financial outcomes.

\section{Conclusions}

A systematic qualitative analysis of interviews and focus groups of administrators and physicians at 6 study sites that successfully implemented ambula- 
tory EHR systems revealed common themes related to fundamental personal and practice changes for physicians. These changes have implications for clinical practice overall and may hinder successful utilization of full EHR functionality. For example, changes in physician practice patterns require a cultural shift in terms of professional hierarchy, clinical workflow, and medical training. By outlining the elements of this cultural shift, our study provides valuable information to EHR change managers, such as health system administrators and state-level HIT-REC offices.

The authors are extremely grateful to the organizations and informants who participated in this study and to the health system members of the Project Advisory Team. The authors also thank the research team members, Drs. Paula Song, Julie Robbins, and Deena Chisolm; research assistants Annemarie Hirsch, Maria Jorina, Nina Kowalczyk, Trevor Young, Emily Kathryn Orcutt Knecht, and Malissa Frost; and clinical consultants Drs. John Mahan, David Rich, and Scott Holiday, all of whom were affiliated with The Ohio State University during the study.

\section{References}

1. Hsiao C, Hing E, Socey TC, Cai B. Electronic health record systems and intent to apply for meaningful use incentives among office-based physician practices: United States, 2001-2011. NCHS Data Brief 2011;79:1-8.

2. Kokkonen EW, Davis SA, Lin H, Dabade TS, Feldman SR, Fleischer AB. Use of electronic medical records differs by specialty and office settings. J Am Med Inform Assoc 2013;20:e33-8.

3. Rao SR, Desroches CM, Donelan K, Campbell EG, Miralles PD, Jha AK. Electronic health records in small physician practices: availability, use, and perceived benefits. J Am Med Inform Assoc 2011;18: 271-5.

4. Simon SR, McCarthy ML, Kaushal R, et al. Electronic health records: which practices have them, and how are clinicians using them? J Eval Clin Pract 2008;14:43-7.

5. Blumenthal D, DesRoches C, Donelan K. Health information technology in the United States: where we stand, 2008. Health Information Technology Initiative, Massachusetts General Hospital and the School of Public Health and Health Services at George Washington University. Princeton (NJ): Robert Wood Johnson Foundation; 2008.

6. Burt CW, Hing E, Woodwell D. NCHS Health EStat. Electronic medical record use by office-based physicians: United States, 2005. Hyattsville (MD): National Center for Health Statistics, Centers for Disease Control and Prevention; 2006. Available from: http:// www.cdc.gov/nchs/data/hestat/electronic/electronic.htm. Accessed November 10, 2014.
7. DesRoches CM, Campbell EG, Rao SR, et al. Electronic health records in ambulatory care- a national survey of physicians. N Engl J Med 2008;359:50-60.

8. Lorenzi NM, Kouroubali A, Detmer DE, Bloomrosen $M$. How to successfully select and implement electronic health records (EHR) in small ambulatory practice settings. BMC Med Inform Decis Mak 2009;9:15.

9. Greiver M, Barnsley J, Glazier RH, Moineddin R, Harvey BJ. Implementation of electronic medical records: theory-informed qualitative study. Can Fam Physician 2011;57:e390-7.

10. Ash JS, Bates DW. Factors and forces affecting EHR system adoption: report of a 2004 ACMI discussion. J Am Med Inform Assoc 2005;12:8-12.

11. Simon SR, Kaushal R, Cleary PD, et al. Correlates of electronic health record adoption in office practices: a statewide survey. J Am Med Inform Assoc 2007;14: $110-7$.

12. Boonstra A, Broekhuis M. Barriers to the acceptance of electronic medical records by physicians from systematic review to taxonomy and interventions. BMC Health Serv Res 2010;10:231.

13. McGinn CA, Grenier S, Duplantie J, et al. Comparison of user groups' perspectives of barriers and facilitators to implementing electronic health records: a systematic review. BMC Med 2011;9:46.

14. Menachemi N, Brooks R. Reviewing the benefits and costs of electronic health records and associated patient safety technologies. J Med Syst 2006; 30:159-68.

15. Wang SJ, Middleton B, Prosser LA, et al. A costbenefit analysis of electronic medical records in primary care. Am J Med 2003;114:397-403.

16. Hillestad R, Bigelow J, Bower A, et al. Can electronic medical record systems transform health care? Potential health benefits, savings, and costs. Health Aff (Millwood) 2005;24:1103-17.

17. Bar-Dayan Y, Saed H, Boaz M, et al. Using electronic health records to save money. J Am Med Inform Assoc 2013;20:e17-20.

18. Shekelle PG, Morton SC, Keeler EB. Costs and benefits of health information technology. Evid Rep Technol Assess (Full Rep) 2006;(132):1-71.

19. Adler-Milstein J, Salzberg C, Franz C, Orav EJ, Newhouse JP, Bates DW. Effect of electronic health records on health care costs: longitudinal comparative evidence from community practices. Ann Intern Med 2013;159:97-104.

20. Bonner LM, Simons CE, Parker LE, Yano EM, Kirchner JE. 'To take care of the patients': Qualitative analysis of Veterans Health Administration personnel experiences with a clinical informatics system. Implement Sci 2010;5:63.

21. Lau F, Kuziemsky C, Price M, Gardner J. A review on systematic reviews of health information system studies. J Am Med Inform Assoc 2010;17:637-45. 
22. Poon EG, Wright A, Simon SR, et al. Relationship between use of electronic health record features and health care quality: results of a statewide survey. Med Care 2010;48:203-9.

23. Miller WL, Crabtree BF. Doing qualitative research. Vol. 3. Thousand Oaks (CA): Sage Publications; 1999.

24. McCracken G. The long interview. Vol. 13. Thousand Oaks (CA): Sage Publications; 1988.

25. Glaser B, Strauss A. The constant comparative method of qualitative analysis. In: The discovery of grounded theory: strategies for qualitative research. New York: Aldine de Gruyter; 1967:101-15.

26. Constas MA. Qualitative analysis as a public event: the documentation of category development procedures. Am Educ Res J 1992;29:253-66.

27. Hayden SR, Jouriles NJ, Rosen P. Requiem for "non-urgent" patients in the emergency department. J Emerg Med 2010;38:381-3.

28. McAlearney AS, Song PH, Robbins J, et al. Moving from good to great in ambulatory electronic health record implementation. J Healthc Qual 2010;32:41-50.
29. Nambisan P, Kreps GL, Polit S. Understanding electronic medical record adoption in the United States: communication and sociocultural perspectives. Interact J Med Res 2013;2:e5.

30. Rogers E. Diffusion of innovations. 4th ed. New York: Free Press; 1995.

31. Maxson E, Jain S, Kendall M, Mostashari F, Blumenthal D. The Regional Extension Center Program: helping physicians meaningfully use health information technology. Ann Intern Med 2010;153:666-70.

32. Keenan CR, Nguyen HH, Srinivasan M. Electronic medical records and their impact on resident and medical student education. Acad Psychiatry 2006;30:522-7.

33. Stephens MB, Gimbel RW, Pangaro L. Commentary: The RIME/EMR scheme: an educational approach to clinical documentation in electronic medical records. Acad Med 2011;86:11-4.

34. Peled JU, Sagher O, Morrow JB, Dobbie AE. Do electronic health records help or hinder medical education? PLoS Med 2009;6:e1000069.

35. Frankovich J, Longhurst CA, Sutherland SM. Evidence-based medicine in the EMR era. N Engl J Med 2011;365:1758-9. 